\title{
IT, TV and Time Displacement: What Alexander Szalai Anticipated but Couldn't Know
}

\author{
John P. Robinson
}

Accepted: 29 January 2010/Published online: 13 July 2010

(C) The Author(s) 2010. This article is published with open access at Springerlink.com

The study of how people spend time dates back more than 100 years. Serious attention to its societal policy implications was undertaken in Soviet Russia soon after its revolution in the early 1920s and continued into the 1970s (Zuzanek 1980). These were preludes of the masterfully coordinated Multinational Time-Budget Research Project. The project was the brainchild organized by Hungarian Professor Alexander Szalai (1972), a giant of a man, not just physically, but intellectually, socially and politically as well.

An internationally distinguished mathematician, Szalai had the vision to understand how applying the full measurement properties of the classic quantitative variable of time to how people spend it had enormous scientific, policy and philosophical implications. One particular such advantage of time was its "zero-sum" property-one that allows analysts to identify the trade-offs in daily life as new household technologies, public policy innovations or socio-economic conditions diffuse through society. This feature is particularly appropriate for testing a major hypothesis of activity displacement, namely that of "functional equivalence"-a feature discussed in more detail shortly in the context of the two major innovations in household communications technology in the second half twentieth century, namely television and information technology (IT).

In the process of laying out all the detailed empirical and operational features of his path-breaking study (which was also the first social science project to be conducted across the virtually impenetrable "Iron Curtain"), Szalai devised an elegant coding scheme to allow comparison of all daily activity. It is a scheme that not only worked in the 1965 study across both socialist and capitalist societies then, but has been similarly successful in subsequent studies in third-world countries in Asia, Africa and Latin America.

The first digit of Szalai's comprehensive two-digit code shown in Table 1 first divided daily activity into ten distinct categories, moving from paid work (codes 01-09) at the top to mostly passive free time activities (codes 90-99) at the bottom (including reading and conversations, as well as TV and relaxation). Personal care (codes 40-49) was in the middle of this scheme, flanked by family care activities (codes 10-39) on one side and by free time activities (codes 60-69) on the other.

J. P. Robinson ( $($ )

University of Maryland, College Park, MD 20742, USA

e-mail: robinson@socy.umd.edu; jpr@umd.edu 
Table 1 The Szalai 1965 twodigit activity code, updated to include IT codes 53, 56, 57 and 58

00-49 NONFREE TIME

50-99 STUDY AND FREE TIME

\section{0-09 PAID WORK \\ 00 (Not Used) \\ 01 Main Job \\ 02 Unemployment \\ 03 (Not Used) \\ 04 (Not Used) \\ 05 Second Job \\ 06 Eating at work \\ 07 Before/after work \\ 08 Breaks \\ 09 Travel/to-from work}

10-19 HOUSEHOLD WORK

10 Food preparation

11 Meal cleanup

12 Cleaning house

13 Outdoor cleaning

14 Clothes care

15 Car repair

16 Other repairs

17 Plant care, gardening

18 Pet care

19 Other household

20-29 CHILD CARE

20 Baby care

21 Child care

22 Helping/teaching

23 Talking/reading

24 Indoor playing

25 Outdoor playing

26 Medical care-child

27 Other child care

28 (Not used)

29 Travel/child care

\section{0-39 OBTAINING GOODS/ SERVICES}

30 Everyday (food) shopping

31 Durable/house shop

32 Personal services

33 Medical appointments

34 Govt/financial services

35 Repair services

36(Not Used)

37 Other services

\section{0-59 EDUCATIONAL}

50 Students classes

51 Other classes

52 Homework

53 Internet (WWW) use

54 Library use

55 Other education

56 Email/IM

57 Computer games

58 Other computer use

59 Travel/education

60-69 ORGANIZATIONAL

60 Professional/Union

61 Special interest

62 Political/civic

63 Volunteer helping

64 Religious groups

65 Religious practice

66 Fraternal

67 Child/youth/family

68 Other organizations

69 Travel/organizational

70-79 ENTERTAINMENT/ SOCIAL

70 Sports events

71 Entertainment

72 Movies (not videos)

73 Theater

74 Museums

75 Visiting

76 Parties

77 Bars/lounges

78 Telephone/Cell phone

79 Travel/social

\section{0-89 RECREATION}

80 Active Sports

81 Outdoor

82 Walking/hiking

83 Hobbies

84 Domestic crafts

85 Art

$86 \mathrm{Music} / d r a m a / d a n c e$

87 Games 
Table 1 continued

00-49 NONFREE TIME 50-99 STUDY AND FREE

TIME

\begin{tabular}{|c|c|}
\hline 38 Errands & 88 Other recreation \\
\hline 39 Travel/goods and services & 89 Travel/recreation \\
\hline $\begin{array}{l}\text { 40-49 PERSONAL NEEDS AND } \\
\text { CARE }\end{array}$ & 90-99 COMMUNICATIONS \\
\hline 40 Washing, hygiene, etc. & 90 Radio \\
\hline 41 Medical care & $91 \mathrm{TV}+$ videos \\
\hline 42 Help and care to others & 92 Records/tapes \\
\hline 43 Meals at home & 93 Read books \\
\hline 44 Meals out & 94 Read magazines/etc. \\
\hline 45 Night sleep & 95 Reading newspaper \\
\hline 46 Naps/day sleep & $\begin{array}{l}96 \text { Conversations (face-to- } \\
\text { face) }\end{array}$ \\
\hline 47 Dressing/grooming etc. & 97 Writing letters \\
\hline 48 Private, no report (sex) & 98 Think/relax \\
\hline 49 Travel/Personal care & 99 Travel/communication \\
\hline
\end{tabular}

Moreover, the ten main headings can also be conveniently split into the four "super categories' identified by Aas (1978):

1) Paid work (codes 01-09)

2) Unpaid work (10-19,20-29,30-39)

3) Personal care (40-49)

4) Free time (codes 60-69,70-79,80-89,90-99)

Subsumed under nine of these ten main headings (housework codes 10-19 excluded) in Table 1, a second_9 code could be employed to capture the travel associated with each category, so that it can be added together to calculate all travel during the day; or it could be incorporated into the related activities themselves. Each of the second-digit categories was used to identify important activities with the ten types, as in separating cooking (code 10) from cleaning (code 12) in the 1 housework category, or distinguishing sleeping (45) from eating (43) in the 4 personal care category.

The one category that least conveniently fits into these super headings is educational activity, codes 50-59. This was and is still a difficult heading to classify, since its functions have changed somewhat since the 1960s. First, while most education classes and instructional activity (codes 50-52, 54) were discretionary and for leisurely enlightenment purposes then (particularly in Eastern European countries), most such classes today are those taken for credit as a way toward gradual job improvement. Today, we in the West therefore consider them as related more to paid work. The other main activity in the 50's category was code 55 mainly for use of the library, which probably continues to be primarily leisurely, fitting in with in reading books and other printed matter (codes 93-95).

This diversity, combined with the paucity of categories of educational activity is further reflected in the large number of basically unused codes in this category (codes 53, 56, 57, 58). In other words, there was something of a vacuum, opening or flexibility in the Szalai master scheme. Thus, this vacuum provides a convenient way to incorporate most of the (home-based) changes brought about by the computer revolution in personal/home computers in the 1970s and 80s and the Internet in the 1990s, using Szalai's basically unused 
codes, One wonders whether he was anticipating this future information transformation by these gaps in his coding scheme.

This brings us to the question, then, of what are the consequences of these home information technologies (IT) for people's use of time in terms of time displacement or "functional equivalence" This is of particular interest because the new IT has the ability to affect such a broad range of daily activities and functions, from allowing telecommuting work from home, to Internet shopping, to taking courses at home, to connecting and networking socially, to following the news, or to playing videogames. Indeed, by 2004 there was evidence presented below that the Internet had become Americans' main source of information for health and jobs and of contact for personal information.

In order to put these questions of the impact of home IT into historic perspective, however, there is the need to examine its possible displacements to those of the earlier revolutionary electronic technology of television. Here we have dramatic evidence of profound differences in people's time use with the arrival of this first technology.

\section{Time Displacement by TV}

Early Studies of TV: As TV was beginning to diffuse in the 1950s, several empirical studies were undertaken by scholars and media organizations to document the enormous effects TV was obviously having on society. However, most of these studies examined only a few daily activities, mainly those mass media most likely to compete with TV-like movies, radio and light reading. The more comprehensive, systematic and successful effort, then, would be undertaken by the Szalai team of multinational researchers in the 1960s who had the larger question on their agenda, namely how people across the globe distribute their time over the full range of everyday activities. The possible effect of the introduction of television on other activities became an obvious by-product of this most ambitious and carefully planned project (Robinson 1972).

According to the "functional equivalence" hypothesis, a popular new technology like TV should replace those activities whose functions were served by previous technologies, as when the automobile (or "horseless carriage") replaced the horse, or when radio was thought to have displaced the early phonograph or other forms of home music "production" (including playing of instruments and singing, Postman 1985). The expectation that time now spent with television would displace other platforms of mass entertainment, such as radio, movies and light fiction was the focus of many early empirical studies of TV's impact, such as the long-term studies of "Videotown" (New Brunswick, New Jersey). Indeed, these and other similar studies (e.g., Bogart 1956; Coffin 1954; Schramm et al. 1961), some of which were panel studies needed to support causal inferences, turned up results quite consistent with the hypothesis (Weiss 1969).

What these media studies were unable to capture with their collection of mainly measures of media activity, however, were the many other daily activities that could be affected, those that were less obviously entertainment equivalents. Much speculation focused-and still does-on how TV might affect social life, particularly visits with friends and neighbors, since one could now engage in on-screen "visiting" with entertainers and other celebrities in one's own home.

Analyses from Szalai's multinational diary study from 1965 have suggested that television's impact did indeed spill over significantly onto these other activities (Robinson 1972). Figure 1 shows the average time differences across all activities summed across all 12 nations surveyed. It shows a consistent and pervasive pattern of suggested activity trade-offs 


\section{MASS MEDIA}

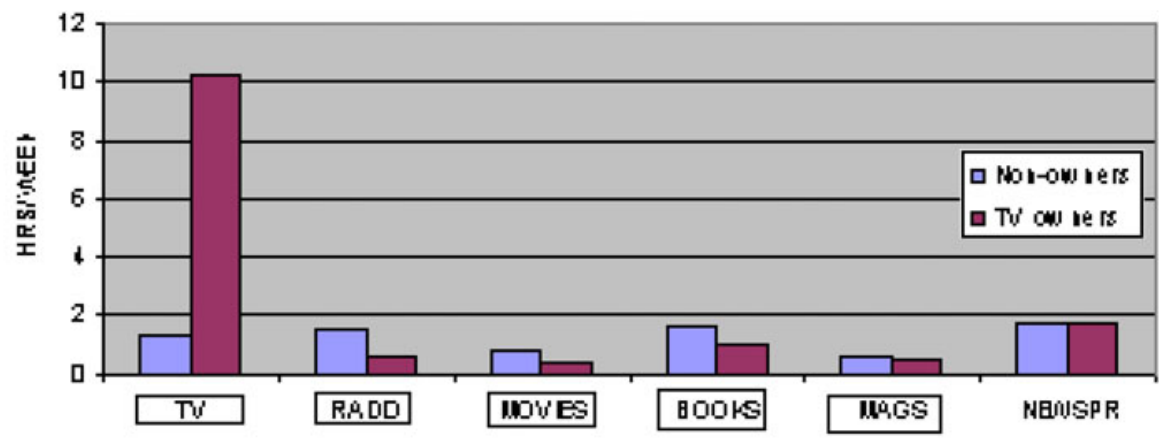

2. OTHER FREE ACTIVTTIES

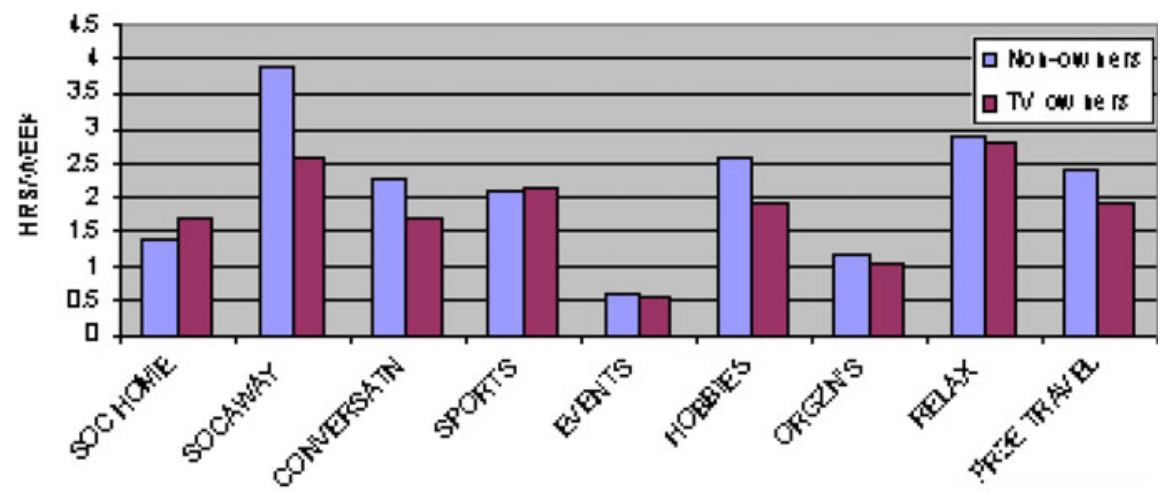

\section{HOH-FREE ACTIVITIES}

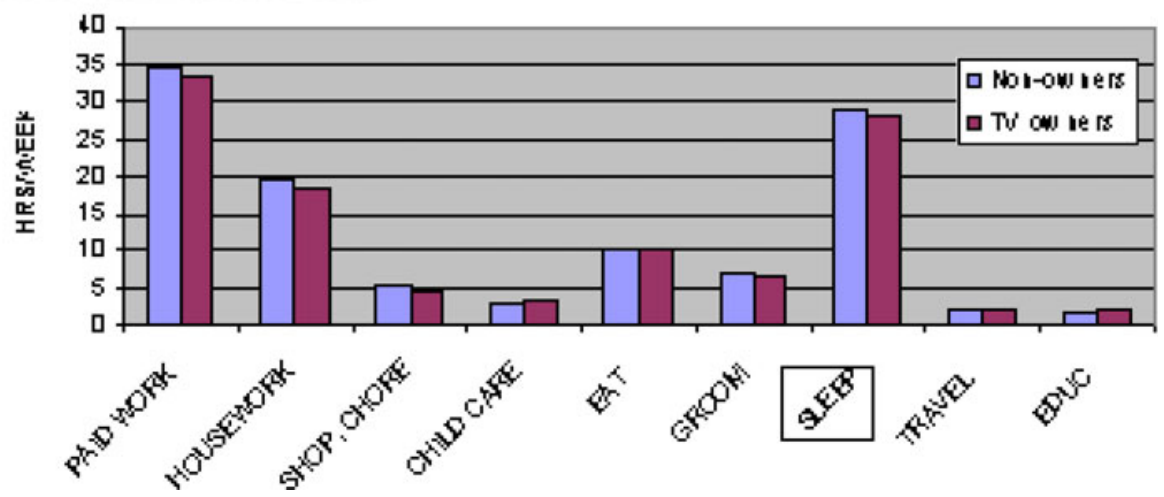

Fig. 1 Differences in activities between TV owners and non-owners (12-nation data in hours per week: 1965)

to accommodate the new chunk of nearly 90 daily minutes now devoted to TV. That is more than $10 \mathrm{~h}$ of the $168 \mathrm{~h}$ of the week, which translates to almost $10 \%$ of people's time awake.

Figure 1 shows that TV owners in almost all of the 12 countries reported spending less time across three kinds of activities: 
(1) "Functionally equivalent" mass media activities, like radio, movies and light-fiction, as established by the Videotown and other studies noted above. Figure 1 shows TV owners were spending about $60 \%$ less daily time radio listening (along with an even larger decline in listening as a "secondary activity"), 53\% less time at the movies, and $30 \%$ less time in book and magazine reading. (The reduction in newspaper reading (as discussed further below) was not yet evident, perhaps because most TV content was designed as entertainment rather than news). However, this decline in other media accounted for only $2 \frac{1}{2} \mathrm{~h}$ a week, compared with the nearly 10 -h increase in TV viewing. Thus, many non-media activities were different as well, especially the lower figures for.

(2) Social activities outside the household (offset somewhat by higher in-home visiting or social contact within the TV household itself). This may be indicative of an indirect functional equivalent, in the form of "visiting" with the characters on the screen. But this additional lower visiting (and its attendant travel) also accounted for another $2 \frac{1}{2} \mathrm{~h}$ decline, meant that about half of the new viewing time also had to come from activities outside free time.

(3) Non-free time activities, particularly sleep, grooming, gardening, and laundry, were also were systematically lower for TV owners. While these are harder to fit under the functional equivalence umbrella, they seem to have a perhaps discretionary character as far as time displacement is concerned. The combined lower figures on these nonfree activities was closer to $4 \mathrm{~h}$.

Again, this tripartite pattern could be found across all 12 individual countries in the Szalai study, in spite of the large national variance in TV diffusion and ownership in the mid-1960s-which ranged from $28 \%$ in Bulgaria to $49 \%$ in the Soviet Union to $80 \%$ in West Germany and to $95 \%$ in the US. Importantly, the patterns in Fig. 1 also held after MCA adjustment for education, age and other strong demographic predictors of viewing in each country (Andrews et al. 1973).

To put it in another context, the free-time differences between owners and non-owners in Fig. 1 are up to twice as large as the free-time differences between men and women in these countries in the 1960s. Nonetheless, it should be noted that the combined 12-nation data in Fig. 1 come from single-time surveys and not from the kind of panel studies that would be needed to support causal arguments.

Indeed, data from subsequent national diary studies after 1965 (now expanded to include more than 30 countries, 23 of which are shown in Table 1 below) suggest that TV has had more temporal impact on daily life in society than any other technology or set of technologies in the last century. In contrast, most of these other "productive" technologies, like automobiles or washing machines, seem more closely linked to increases in output (miles driven, for example, or clothes cleaned) than to savings in time. These conclusions can also be inferred from the 1965 Szalai study, which compared countries high and low in these technologies. Indeed, Eastern European countries in the study had far fewer automobiles and appliances, yet about the same time was spent traveling and doing housework as in countries in the West.

At the same time, these initial 1960s diary findings in Fig. 1 fit another pattern, namely one of time constancy. That is, no matter whether the programming was capitalist or socialist, whether the broadcast day was almost full time or confined to evening "primetime" hours, viewing time for set owners averaged an hour and an half per day. It appeared as though TV had reached its asymptote in the 1960s, on a per-set-owner basis (Robinson 1968, 1981). 
More Recent Time Trends: The initial time transformations in Fig. 1, however, have not remained static, but have continued since the 1960s especially in the US, as documented in subsequent diary studies conducted each decade since the 1960s. Figure 2 shows US, TV viewing as a primary activity has steadily increased from about 10 weekly hours in the 1960s (among those working-aged 18-64) to almost $15 \mathrm{~h}$ in 1975 (mainly, it seems, in response to color TV), to $15 \mathrm{~h}$ again in 1985, and to $16 \mathrm{~h}$ in 1995 and 2005. Indeed, the 5-h increase in TV time from 1965 to 1975 equaled the total 5-h increase in free time over that 1965-75 decade.

Altogether, that 5-h weekly increase now meant that the 1975 time people spent viewing TV consumed almost half of their 35-40 h of free time reported in the time diaries-and to more than half of free time, if the $5+$ weekly hours of secondary activity viewing time (shown in the black band in Fig. 2) are also included. (These roughly $5 \mathrm{~h}$ of TV secondary time come from the last US diary study to include secondary activities done in 19982001).

Moving onto multinational twenty-first century data some four decades years after the 1965 data in Fig. 1, Table 2 updates the combined multinational Fig. 1 data by reporting the most recent national diary figures for 23 European and other mainly Western countries (Fisher and Robinson 2009). Here, average viewing time in other countries is somewhat lower than in the US (mainly 8-14 h per week), and with about the same amount (35-40 h) of total free time. In percentage of free time terms, the $40 \%$ figure for the US in Table 2 can be seen as notably higher than in most Western European countries (where it tends to be less than $30 \%$, dipping to less than $20 \%$ in Holland). However, it is lower than in Bulgaria (48\%), Japan (45\%), or most Baltic countries (40-46\%), although all of these countries tend to have somewhat less free time available to watch.

For the US, the overall 6-h US increase in viewing time between 1965 and 2005 was among the most impressive activity changes-for both men and women. It is exceeded over the 1965-2007 period only by the significant effects of the "gender revolution" in the late twentieth century, which resulted in a 7-h weekly increase in women's paid work, a 12-h decrease in women's housework-and in an 8-h decrease in hours of paid work for men vs. about a 4-h increase in their housework (Robinson and Godbey 1999).
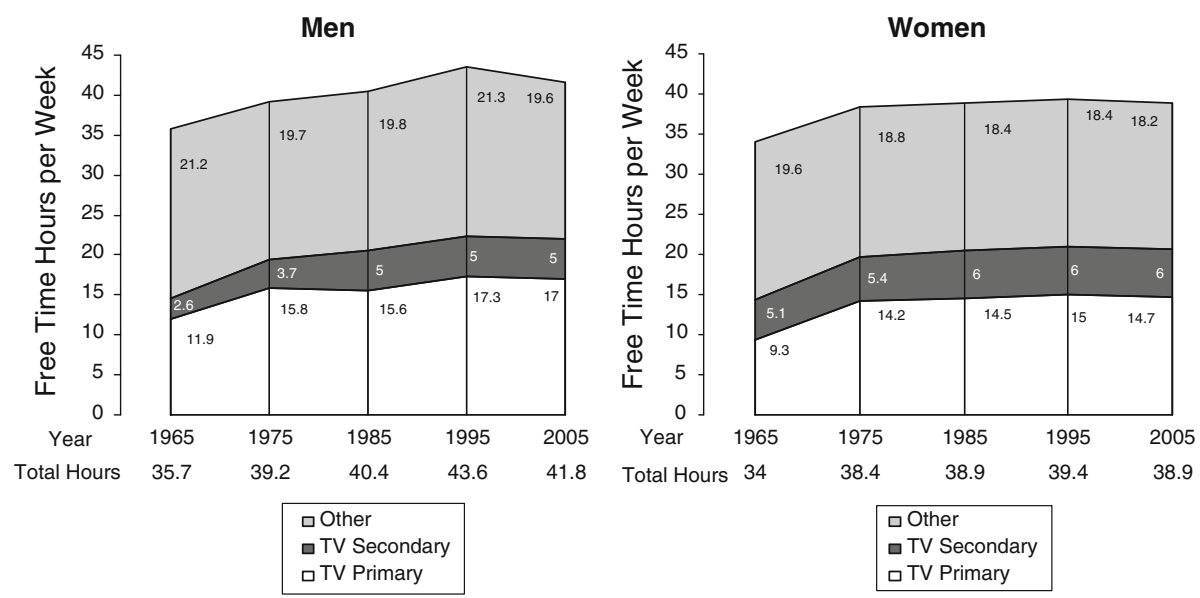

Fig. 2 US 1965-2005 trends in TV and other free time (Ages 18-64, in hours per week) 
Table 2 TV and other free time activities: 1998-2005

\begin{tabular}{lrllllllll}
\hline $\begin{array}{l}\text { In hours per } \\
\text { week) }\end{array}$ & TV & IT & $\begin{array}{l}\text { Read/ } \\
\text { Audio }\end{array}$ & $\begin{array}{l}\text { Social } \\
\text { life }\end{array}$ & $\begin{array}{l}\text { Organ/ } \\
\text { Church }\end{array}$ & Fitness & $\begin{array}{l}\text { Other } \\
\text { Total free } \\
\text { time }\end{array}$ & $\begin{array}{l}\% \mathrm{TV} \\
(\%)\end{array}$ \\
\hline US & 15.6 & 1.2 & 2.3 & 12.1 & 3.6 & 2.1 & 2.4 & $39.3 \mathrm{~h}$. & 40 \\
Canada & 13.5 & 1.7 & 2.3 & 13.7 & 3.2 & 3.1 & 3.8 & 41.4 & 33 \\
Australia & 13.5 & 0.4 & 5.4 & 8.5 & 1.3 & 2.8 & 7.5 & 39.4 & 34 \\
UK & 15.6 & 1.2 & 3.2 & 12.7 & 1.5 & 3.2 & 3.5 & 40.9 & 38 \\
Netherlands & 8.1 & 1.8 & 7.7 & 17.2 & 3.2 & 1.8 & 2.9 & 42.7 & 19 \\
Belgium & 15.4 & 2.6 & 3.0 & 15.0 & 0.8 & 3.1 & 4.4 & 44.3 & 35 \\
France & 13.2 & 0.6 & 2.6 & 13.3 & 1.3 & 3.0 & 3.9 & 37.9 & 35 \\
Spain & 12.0 & 1.1 & 2.0 & 11.5 & 1.4 & 5.2 & 4.1 & 37.3 & 32 \\
Italy & 10.6 & 0.7 & 2.4 & 13.4 & 1.8 & 3.6 & 4.9 & 37.4 & 28 \\
Germany & 12.1 & 2.0 & 4.5 & 14.6 & 2.2 & 3.5 & 4.6 & 43.5 & 28 \\
Norway & 12.6 & 1.3 & 4.4 & 18.0 & 1.5 & 3.9 & 3.6 & 45.3 & 28 \\
Sweden & 11.9 & 1.4 & 3.8 & 13.2 & 1.6 & 4.0 & 4.9 & 40.8 & 29 \\
Finland & 14.7 & 0.9 & 5.8 & 11.9 & 2.0 & 4.3 & 5.0 & 44.6 & 33 \\
Estonia & 15.4 & 0.4 & 4.8 & 6.9 & 1.8 & 2.7 & 3.6 & 35.6 & 43 \\
Lithuana & 15.3 & 0.8 & 3.1 & 7.1 & 1.9 & 2.3 & 2.5 & 33.0 & 46 \\
Latvia & 13.8 & 0.5 & 3.3 & 8.5 & 1.4 & 3.4 & 3.6 & 34.5 & 40 \\
Poland & 15.3 & 1.1 & 3.5 & 10.1 & 2.9 & 3.2 & 2.8 & 38.9 & 39 \\
Slovenia & 13.2 & 0.7 & 3.1 & 11.8 & 1.4 & 4.1 & 4.8 & 39.1 & 34 \\
Bulgaria & 16.6 & 0.1 & 2.5 & 8.9 & 1.1 & 3.0 & 2.6 & 34.8 & 48 \\
Turkey & 13.8 & NA & 1.8 & 18.0 & 4.4 & 0.8 & 5.9 & 44.7 & 31 \\
Korea & 14.6 & 1.5 & 2.0 & 12.8 & 0.5 & 2.9 & 3.1 & 37.4 & 39 \\
Japan & 13.9 & 1.2 & 2.9 & 5.3 & 0.6 & 2.1 & 5.1 & 31.1 & 45 \\
Brazil & 13.3 & 0.5 & 1.5 & 12.5 & 3.2 & 1.6 & 8.7 & 41.3 & 32 \\
\hline & & & & & & & & &
\end{tabular}

The situation for newspapers: Perhaps the most prominent activity decline during this period of increased TV viewing time since 1965, however, is another mass medium, namely newspaper reading-one seemingly unaffected by TV in Fig. 1. The steady and dramatic US newspaper time decline (shown more steadily and dramatically in the General Social Survey (GSS) estimated newspaper-use data in Robinson and Martin (2009) provides further support for the functional equivalence argument. This drop is likely related to the rising prominence of TV news in the late 1960s, which may have been abetted by the rise (particularly in the US) of the so-called "news doctors," industry consultants who recast local TV news content in more appealing formats for local audiences.

Summary and Conclusions about TV and Time: These periodic multinational time-diary data since the original Szalai study indicate that TV has had more impact on daily use of time than other (primarily productive) household technologies, and that it continues to consume about half of people's free time in the US and more than $30 \%$ in other Western countries. From the beginning, TV did seem to draw time away from functionally equivalent activities, like movies, radio and print fiction-and more recently from newspapers. It also appears to have drawn time from social and personal care activities that are harder to argue to be functional equivalents, like sleep and hobbies. Main gains in viewing time occurred in the US in the 1970s, apparently related to the arrival of color TV, but with smaller inroads on free time since then. 


\section{Time on the Internet and Other IT}

Fast forward again to the new millennium, and to the newest communications technologies to challenge TV and other daily activities, namely the Internet and other information technologies (IT). How do various social and media activities differ between Internet users and nonusers? In the context of the "functional equivalence" hypothesis, its reach seems much broader, as it can directly affect social as well as media life to perform the same functions for users as did TV and the older technologies (Wright 1986; McQuail 1994). The Internet can combine and meld the functions and features of both personal and mass forms of communication. When one turns to the question of how Internet use may affect daily activities - and communication activities in particular-it becomes clear that as Internet usage becomes more prominent, its potential displacement of alternative media and other activities becomes more substantial.

To maintain continuity with Fig. 1, the main data set examined here is the 2003-07 American Time-Use Survey (ATUS), conducted by the US Census Bureau for the Bureau of Labor Statistics (BLS). The ATUS has examined all daily activity using 24-h time diaries, much like those underlying Fig. 1. Since these results are largely consistent with analyses from other national time surveys (especially the U.S. General Social Survey (GSS) described below), as well from a number of other data sources. All seem to point to the same conclusion-namely one of minimal impact of IT on time, especially in contrast to all the changes apparent in relation to Fig. 1.

This ATUS analysis of the comparison of IT users and nonusers are first put in the context of the earlier studies of activities possibly displaced by the Internet and other IT.

Early Studies of Internet Impact: Initial speculation on the effects of the Internet has tended to focus on social life and personal communication on the one hand, and mass communications on the other. The content of communication on both types of media channels can possibly be more effectively or attractively conveyed by the Internet than by previous media, so that there are reasons to expect many of the same sorts of differences for the Internet as were found for television. More specifically, one expects to find general declines in social life and in usage of prior mass media among Internet users.

At first, three widely publicized studies of early Internet impact reported results consistent with that hypothesis of declining social life and media use. Both Cole et al. (2001) and Nie and Erbring (2000) each conducted national studies with more than 2000 respondents, and they reported declines in social life, television viewing, and other activities among IT users that could be considered functionally equivalent. Moreover, their results are consistent with the earlier and more carefully-designed single-community study of Kraut et al. (1998).

However, studies that subsequently used a less ambitious set of questions and research designs produced more mixed results (e.g. Wellman et al. 2001) or reversals (Kraut et al. 2002). These include the:

(1) Pew Center for Public Opinion Research national surveys since 1995 related to IT diffusion and use. A main value of these earlier Pew Center surveys was that they asked intensive questions about social and media activity "yesterday," as well as estimate questions on their behavior over longer time periods. Robinson et al. (1997), Robinson and Kestnbaum (1999) and Robinson et al. (2000) presented several analyses based on these Pew data, and found that Internet and IT users actually were significantly more likely to use print media, radio newscasts, and movies than nonusers, and they were not significantly less likely to engage in social activities. 
(2) Six national time-diary studies (three in the U.S., and one each from Canada, the U.K. and the Netherlands) as analyzed by Robinson and DeHaan (2006). They also found few consistent activity differences-especially after MCA adjustment for other predictors In other words, hardly any time differences could be found between Internet users and nonusers for specific activities, even for watching TV. Moreover, they also found higher reading among Internet users. Similar results were found in the most sophisticated diary study done in the UK, with a 1-year panel design using weekly diaries. (Gershuny 2003).

(3) Robinson and DeHaan (2006) also reviewed 14 studies using time-estimate questions that showed even stronger and more consistent evidence for Internet users being more social in their activities and attitudes than nonusers, not just in the US but seven other countries as well.

Thus, these results cast serious doubt on the usefulness of the functional equivalence thesis in respect to a more engaging Internet usage reducing social life, or mass media use. Perhaps, the more remarkable and counterintuitive findings (given the zero-sum nature of time as a variable) concern the higher reading times among Internet users, which continues after multivariate adjustments for various background predictors are taken into account.

These results of basically no difference appeared again in a separate national study over period since 2000, namely the US General Social Survey (GSS). The GSS is considered to be the major monitoring instrument for documenting social change since 1972. GSS employed time estimate questions, but these faced the functional equivalence argument more directly, by asking questions about both Internet use and other media use about the same topics (health, jobs and personal contacts) across time. An outline of these questions and their results is presented, and in more detail in Robinson and Martin (2008, 2009).

The new GSS questions on health, jobs and personal contacts had the advantage of asking not only about how much the Internet was used for these purposes, but how much previous media (TV, newspapers, personal contacts) were as well. That allowed one to not only chart the rise of the Internet in serving these functions, but to see how much use of the previous media for this function was affected in addition. For example, did using the Internet for health result in decreased use of TV, newspapers and the like.

In brief, these results did show the expected increased use of the Internet for these functions since 2000-indeed to the point that the Internet became the primary source of such information. In other words, this was evidence that the Internet had become a most powerful medium of communication. At the same time this occurred, however, there was no decline in the extent of use by the earlier media. In other words, other media use was not different across time as the Internet diffused, nor different across people.who were higher in their IT use.

The GSS also repeated many of the traditional behavior questions it had asked prior to the Internet becoming a viable medium, such as (1) visits with other people, frequency of sex and attending church as social behaviors, and (2) reading newspapers and watching TV as media behaviors. As with the new GSS questions, there was no consistent decline in either the social or media questions across time (as Internet use increased), nor among respondents who used the Internet, nor used it more (Robinson and Martin (2008, 2009).

In other words, in these 2000-2006 national GSS studies, Internet use was not consistently correlated with significantly lower levels of socializing or other social activities like church attendance-nor with lower time using mass communications media. Respondents who spend more time on the Internet did report fewer social visits with relatives, but that was offset by more visits with friends, compared to those who spent no time on IT. 
Overall, then, previous research provides limited evidence that Internet use is associated with lower amounts of time spent at work, in television viewing, and in sleep. However, like the findings relating Internet use and social life in Robinson and DeHaan (2006), the evidence is scattered, often insignificant and sometimes simply explained by background factors that predicted IT use.

With this as background, attention now turns to the most recent diary data from the ATUS in Fig. 3.

As in the original Szalai diary data, the times that ATUS respondents spent on all their primary activities can be found at the www.bls.gov website. What is basically involved in Fig. 3, then, is a cross-tabulation of the weekly time ATUS respondents spent on all their primary activities as a function of whether and how much time they spent using IT (not during work time) on that same diary day. To be consistent with Fig. 1, only working-aged respondents are examined, those aged 18-64.

In brief, only one Fig. 3 activity-paid work-shows a notable decrease, one of about $6 \mathrm{~h}$ per week (correlation $=-.08$ ). Just two other activities, child care and sleep, show a decline of $1 \mathrm{~h}$ or more. Moreover, the differences in child care are cut in half if presence of children in the household is taken into account, and for sleep if employment status is taken into account. At the same time, some activities actually show increased time among IT users, including shopping, reading and music listening. These are activities, then, that are positively correlated with IT use, since they are engaged in more by IT users rather than less. Certain other activities are not significantly different for IT users (in spite of the large sample sizes involved), such as grooming, attending events (including movies), organizational activities and telephone or at-home family conversations.

However, the main inhibitor, or competitor, of IT use in Fig. 3 remains paid work. The -.08 correlation between the two remains the most prominent one there, and it is only slightly lowered if one looks only at weekdays, weekends, the employed or teens aged 15-17 or those over age 64. It remains unclear whether the difference is due to (1) working longer hours inhibiting home IT use, (2) home IT users taking more time off from work (or with shorter workweeks), or (3) workers who get enough IT use at work to not need IT use in their nonwork time. However it is clear that paid work time somehow acts as a constraint on use of IT at home. Much the same conclusions emerge when differences by the extent of IT use on the diary day are examined, which show little of expected monotonicity (in the sense of progressive and consistent activity declines (or increases) as IT use increases from nonuse to more than an hour on the diary day).

Here again, then, Fig. 3 provides little evidence of decreased social or media time among IT users, or increasingly decreased times the more IT is reported on the diary day.

\section{Summary and Conclusions}

Support for the argument that IT use results in, or is even associated with, lower time in social and media activities is not found in the ATUS, a finding which is in keeping with most of the previous literature in the field (including the several studies conducted in other countries). The results are consistent with Hampton et al.'s (2009) more recent study of IT use and social isolation.

In the ATUS study of daily activities, Internet use was actually associated with increased usage of reading, radio listening and some other behaviors. The main difference between users and nonusers in the ATUS was with time at paid work, a relation that is only partially explained by higher Internet use by teens and on days off from work. How IT use 


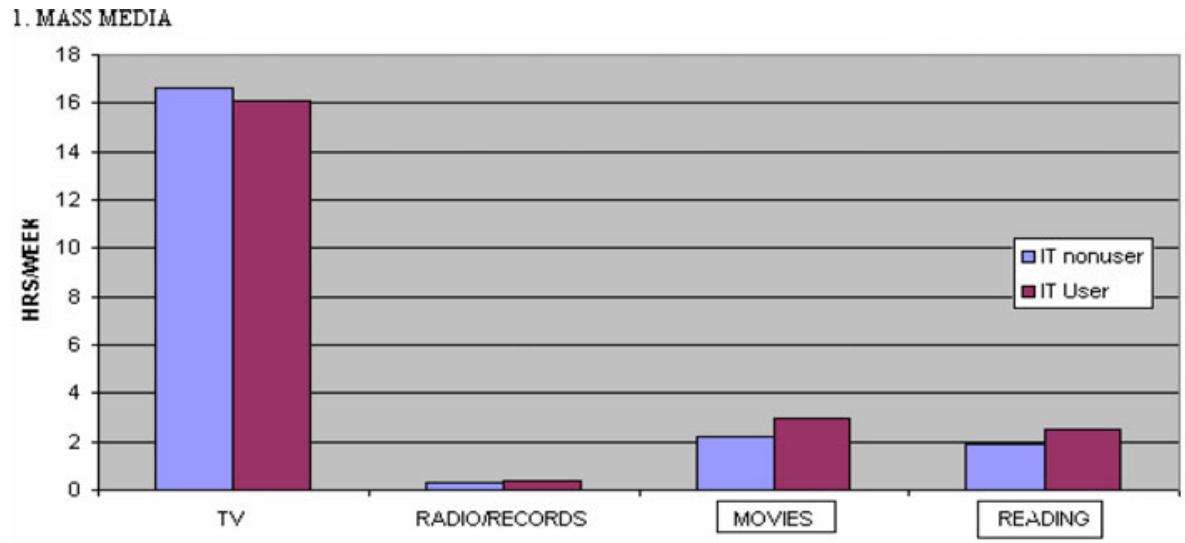

\section{OTHER FREE ACTTVTIIES}

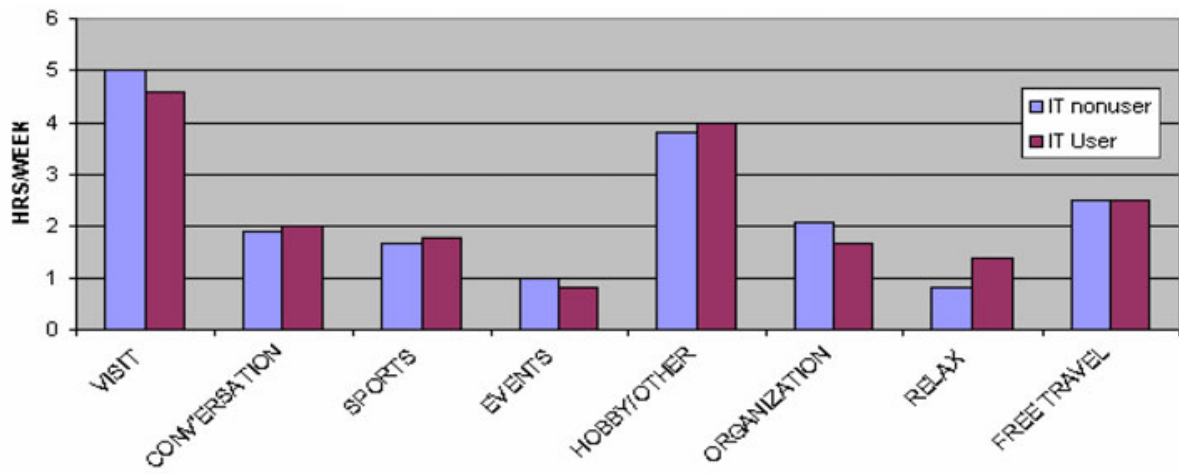

\section{NON-FREE ACTTVTTIES}

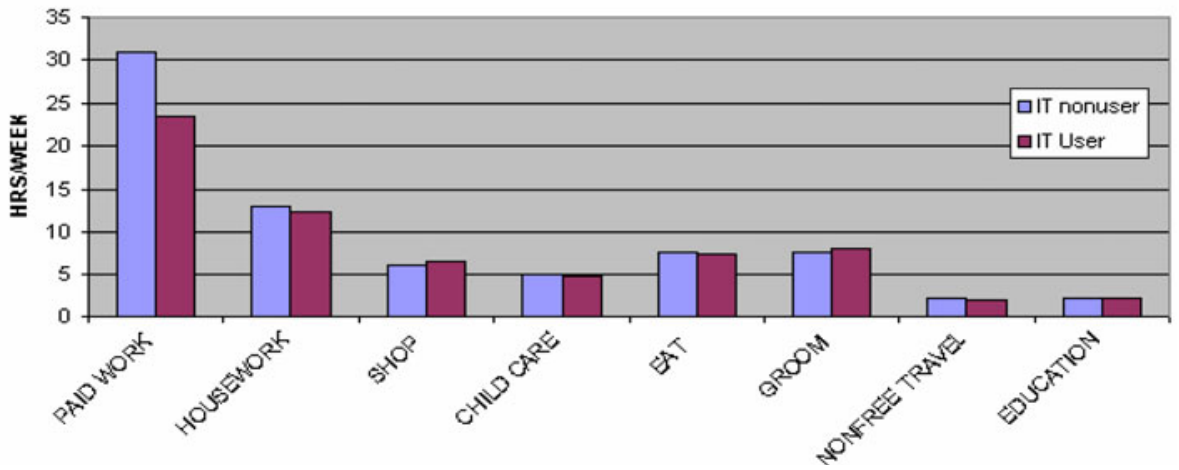

Fig. 3 Difference in activities between IT users and nonusers (US only: ATUS 2003-07 data in hours per week)

relates so strongly with less work time is unclear, but it suggests that IT users seek to verify information from one medium to another.

In neither national study since 2000 , then, does one find any notable evidence of social capital being negatively related with use of IT. In marked contrast to the Fig. 1 results from 
the Szalai study, done just in time to capture the changes that appear to have come with $\mathrm{TV}$, the comparison with the new revolutionary technology of IT could not be more striking. The time variable, measured either by the diary or estimate method, seems virtually unmoved when examining the Internet. That is reflected in the ATUS data in Table 2, where it can be seen that TV time in the US today consumes almost ten times as many weekly hours as IT.

At the same time, that does not mean that time is the best measuring rod for assessing IT's impact. The GSS questions on usage of IT for health and job information, and for social communication, all showed that by 2004 the Internet was surpassing previous media in providing these functions, and it seems unlikely that it has decreased since then. At the same time, there was little evidence that that meant that these previous media declined as news or communication sources, consistent with the findings in Table 2. Somehow, the Internet has made its presence felt without disrupting time. Thanks to Szalai's study, we have evidence of how TV stands alone as having revolutionized the use of time.

In addition to documenting the nascent "gender revolution" in work and housework, then, Szalai's pioneering efforts have also resulted in providing clear evidence of how TV has revolutionized daily life. It is a change that truly revolutionized time, perhaps reflecting how TV has universally meant trading short-term pleasure for long-term dysfunction.

Open Access This article is distributed under the terms of the Creative Commons Attribution Noncommercial License which permits any noncommercial use, distribution, and reproduction in any medium, provided the original author(s) and source are credited.

\section{References}

Aas, D. (1978). Studies of time use: problems and prospects. Acta Sociologica, 2, 123-141.

Andrews, F., Morgan, J., \& Sonquist, J. (1973). Multiple classification analysis. Ann Arbor, MI: Institute for Social Research.

Bogart, L. (1956). The age of television: A study of viewing habits and the impact of television on American life. New York: Unger.

Coffin, T. (1954). Television's impact on society. American Psychologist, 10, 630-641.

Cole, J., Suman, J., Schramm, P., Lunn, R., Coget, J., et al. (2001). The UCLA Internet report 2001. Surveying the digital future. Los Angeles: University of California, Los Angeles, Center for Communication Policy.

Fisher, K., \& Robinson, J. (2009). Daily time differences in 17 countries. Social Indicators Research, 93, 1.

Gershuny, J. (2003). Web-use and net-nerds: A neo-functionalist analysis of the impact of information technology in the home. Social Forces, 82(1), 141-168.

Hampton, K., et al. (2009). Social isolation and new technology. Washington DC: Pew Center.

Kestnbaum, M., Robinson, J. P., Neustadtl, A., \& Alvarez, A. S. (2002). IT and social time displacement. IT and Society, 1(1), 21-37.

Kraut, R., Kiesler, S., Boneva, B., Cummings, J., Helgeson, V., \& Crawford, A. (2002). Internet paradox revisited. Journal of Social Issues, 58, 49-74.

Kraut, R., Patterson, M., Lundmark, V., Kiesler, S., Mukophadhyay, T., \& Scherlis, W. (1998). Internet paradox. American Psychologist, 53(9), 1017-1031.

McQuail, D. (1994). McQuail's mass communication theory (4th ed.). London: Sage.

Nie, N. H., \& Erbring, L. (2000). Internet and society: A preliminary report. IT and Society, 1(1), $275-283$.

Nielsen/NetRatings. (1999). TV viewing in Internet households. A report by Nielsen Media Research. Retrieved from http://www.nielsen/NetRatings. (1999). TV viewing in Internet households. A report by Nielsen Media Research. Retrieved from http://www.nielsen-netratings.com/.

Postman, N. (1985). Amusing ourselves to death. New York: Viking.

Robinson, J. P. (1968). Television and leisure time. Public Opinion Quarterly, 33, 210-222.

Robinson, J. P. (1972). Television's impact on everyday life: Some cross-national evidence, Vol. 4. In E. Rubinstein, G. Comstock, \& J. Murray (Eds.), Television and social behavior (pp. 410-431). Washington, DC: Government Printing Office. 
Robinson, J. P. (1981). Television and leisure time: A new tomorrow. Journal of Communication, 31, $120-130$.

Robinson, J. P., Barth, K., \& Kohut, A. (1997). Personal computers, mass media, and use of time. Social Science Computer Review, 15, 65-82.

Robinson, J. P., \& DeHaan, J. (2006). Information technology and family time displacement. In R. Kraut, M. Brynan, \& S. Kiesler (Eds.), Computers, phones and the internet (pp. 51-69). Oxford: Oxford University Press.

Robinson, J. P., \& Godbey, G. (1999). Time for life: The surprising ways Americans use their time. University Park: Pennsylvania State University Press.

Robinson, J. P., \& Kestnbaum, M. (1999). The personal computer, culture and other uses of free time. Social Science Computer Review, Summer, 209-216.

Robinson, J. P., Kestnbaum, M., Neustadtl, A., \& Alvarez, A. (2000). Mass media use and social life among Internet users. Social Science Computer Review, 18(4), 490-501.

Robinson, J. P., \& Martin, S. (2008). IT and activity displacement: Evidence from the general social survey. Social Indicators Research, 91, 115-139.

Robinson, J. P., \& Martin, S. (2009). Of Time and Television. Annals, 625, 74-86.

Schramm, W. L., Lyle, J., \& Parker, E. B. (1961). Television in the lives of our children. Stanford, CA: Stanford University Press.

Szalai, A. (1972). The use of time: Daily activities of urban and suburban populations in twelve countries. Mouton: The Hague.

Weiss, W. (1969). Effects of mass media on communication. In G. Lindzey \& E. Aronson (Eds.), Handbook of social psychology (Vol. 5, pp. 77-195). Reading, MA: Addison-Wesley.

Wellman, B., Haase, A., Witte, J., Hampton, K., et al. (2001). Does the Internet increase, decrease or supplement social capital? Social network, participation and community commitment. American Behavioral Scientist, 45, 437-456.

Wright, C. R. (1986). Mass communication; a sociological perspective. New York: Random House.

Zuzanek, J. (1980). Work and leisure in the Soviet Union: A time-budget analysis. New York: Praeger. 